\title{
PERSEPSI GURU PELATIH DIPLOMA PENDIDIKAN AWAL KANAK-KANAK TERHADAP PENYELIAAN PRAKTIKUM OLEH GURU PEMBIMBING DAN PENSYARAH PENYELIA
}

\author{
Perception of Trainee Teacher from Diploma in Early Childhood Education \\ towards Practicum Supervision among Cooperating Classroom Teacher \\ (CCT) and Supervisors
}

Nor Syazwanie Mohamad Zamal ${ }^{1}$, Mazeni Ismail ${ }^{2}$, Jameyah Sheriff ${ }^{3}$

Kolej Poly-Tech MARA, Kelantan Malaysia ${ }^{1}$, CECD GROUP Malaysia ${ }^{3}$

waniezamal@gmail.com ${ }^{1}$, mazeni@gapps.kptm.edu.my ${ }^{2}$,

jamusm_04@yahoo.com ${ }^{3}$

\section{ABSTRAK}

Kajian ini merupakan satu kajian tinjauan yang dilakukan bagi mendapatkan maklum balas berkaitan persepsi guru pelatih Diploma Pendidikan Awal Kanak-kanak terhadap seliaan praktikum guru pembimbing dan pensyarah penyelia. Kajian ini turut dijalankan bagi mendapatkan peranan pensyarah penyelia dan kesan sesi latihan praktikum yang telah diikuti. Kajian ini melibatkan seramai 87 orang responden yang terdiri daripada guru-guru pelatih semester 6, Diploma Pendidikan Awal Kanak-kanak (BE102) Kolej Poly-Tech MARA Kota Bharu Kelantan dan melibatkan 26 buah tadika swasta berdaftar terpilih. Responden kajian yang dikaji telah menjalani sesi latihan praktikum di TADIKA swasta sekitar 6 buah daerah berbeza di negeri Kelantan. Kaedah kajian ini dikendalikan secara kaedah kuantitatif melalui penggunaan borang soal selidik. Soal selidik kajian terdiri daripada tujuh bahagian merangkumi demografi responden, penempatan praktikum, maklumat TADIKA dan persepsi responden. Dapatan kajian telah dianalisis menggunakan 'Statistical Package 
for the Social Science' (SPSS) versi 21.0. Hasil dapatan kajian mendapati guru pelatih mempunyai persepsi yang tinggi terhadap guru pembimbing di TADIKA dengan purata min, 3.8333 .

Kata kunci: guru pelatih, guru pembimbing, pensyarah penyelia, persepsi, praktikum

\section{ABSTRACT}

This study was a survey conducted to obtain feedback about the perception of Diploma in Early Childhood Education students of cooperating classroom teacher (CCT) and supervisors. This study was also conducted to find the role of supervisors and the effect of the practicum training session that has been undertaken. This study involved 87 respondents consisting of $6^{\text {th }}$ semester trainee teachers, Diploma in Early Childhood Education (BE102) of Kolej Poly-Tech MARA Kota Bharu, Kelantan at 26 selected private kindergartens. They have been sent to 6 different districts in Kelantan. The method of this study was conducted by quantitative method using a bunch of questionnaire. This questionnaire consists of seven sections covering respondent's demographics, practicum placement, information and perception of respondents. The findings were analyzed using Statistical Package for the Social Science (SPSS) version 21.0. The result showed that the trainee teachers have a high perception towards CCT in TADIKA with an average mean 3.833 .

Keywords: trainee teacher, cooperating classroom teacher (cct), supervisors, perception, practical

\section{PENGENALAN}

Perkembangan Pendidikan Awal Kanak-kanak di Malaysia adalah penting untuk memastikan pendidikan awal kanak-kanak memenuhi keperluan Falsafah Pendidikan Negara. Dasar Pendidikan Awal Kanak-Kanak diwujudkan untuk mencapai keperluan menyediakan program pendidikan 
Jurnal Pendidikan Awal Kanak-Kanak Kebangsaan 2017 Special Issue (16-30)

(ISSN 2289-3032 / eISSN 2550-178X)

https://ejournal.upsi.edu.my/journal/JPAK

awal kanak-kanak yang berkualiti bagi membentuk pembangunan modal insan kelas pertama yang produktif di abad ke-21. Aleng (2014) mengatakan bahawa pembinaan modal insan yang berjaya perlu bermula dari awal melalui pendidikan. Hal ini bagi membentuk kanak-kanak yang berjaya kelak. Allen dan Cowdery (2015) mengatakan pengajaran boleh meningkatkan perkembangan dan pembelajaran kanak-kanak. Pengajaran ini sememangnya memerlukan penglibatan guru yang berkualiti dan progresif.

Couse dan Recchia (2015) berpendapat penyediaan guru pendidikan awal kanak-kanak perlu melalui peringkat yang rumit merangkumi penyelidikan dan sokongan teori penyelidik terdahulu bagi mewujudkan pendidik awal yang baik. Morrison (2014) mengatakan bahawa tenaga guru dan pendidik pendidikan awal kanak-kanak yang terlatih akan menjadi faktor utama dalam menyumbang kejayaan pendidikan awal kanak-kanak. Oleh itu kerajaan Malaysia telah menetapkan bahawa pendidik awal kanak-kanak perlu mempunyai kelayakan untuk mendidik kanak-kanak dengan kelayakkan sekurang-kurangnya diploma dalam bidang Pendidikan Awal Kanak-kanak.

Khairul Anwar dan Abu Bakar (2014) mengatakan bahawa latihan praktikum adalah satu komponen yang amat penting untuk menyediakan guru pelatih dengan pengetahuan dan kemahiran yang diperlukan untuk menjadi seorang pendidik. Hal ini secara tidak langsung telah melibatkan guru pembimbing dalam membentuk pendidik awal kanak-kanak yang berkualiti. Oleh itu persepsi guru pelatih terhadap guru pembimbing perlu dinilai.

\section{Kajian Lepas}

Latihan praktikum merupakan komponen penting bagi menyediakan guru pelatih yang berkemahiran tinggi. Namun sesi latihan ini bukanlah semudah yang disangka, pelbagai perkara yang perlu dilalui oleh guru pelatih 
sepanjang menjalani sesi latihan ini. Al-Momani (2016) mengatakan terdapat pelbagai cabaran telah dialami oleh guru pelatih semasa menjalani sesi praktikum. Cabaran utama yang sering dihadapi oleh guru praktikum adalah kesukaran untuk bekerjasama dengan pihak sekolah terutamanya melibatkan pengetua dan guru sekolah. Manakala Normah et. al. (2016) mengatakan terdapat pelbagai cabaran yang perlu dihadapi oleh guru pelatih untuk menyesuaikan diri dengan pengurusan bilik bilik darjah dan persekitaran sekolah ketika menjalani sesi praktikum. Cabaran-cabaran yang dihadapi guru pelatih ini telah menghasilkan persepsi pengalaman yang berbeza oleh mereka. Hal ini bersesuaian dengan kajian yang dijalankan oleh Altan dan Saglamel (2015) dengan mengatakan perspektif guru pelatihan terhadap sesi latihan praktikum yang dijalankan akan memberi kesan terhadap kesan pengajaran mereka. Manakala Ihmeideh dan Coughlin (2015) mengatakan sesi latihan praktikum akan memberikan implikasi yang positif terhadap program pendidikan dan pembangunan professional guru. Busher et. al. (2015) mengatakan persepsi dan pemahaman terhadap pengalaman praktikum perlu dikaji bagi mengetahui tahap pengetahuan mereka terhadap peranan guru sebenar.

\section{Pernyataan Masalah}

Latihan praktikum merupakan suatu pengalaman latihan mengajar yang wajib dilalui oleh seseorang guru pelatih. Miles et. al. (2016) mengatakan latihan praktikum merupakan elemen penting bagi seseorang individu untuk menjadi pendidik. Namun pengalaman ini kadang kala memberikan pengalaman yang negatif terhadap guru pembimbing. Hal ini kerana perlaksanaan latihan praktikum yang kurang baik. Namun, masalah yang dihadapi guru pelatih kurang diketengahkan kerana mereka tidak mengutarakan masalah tersebut kepada pihak kolej. Masalah yang dihadapi oleh guru pelatih kebiasaannya berpunca daripada peranan guru pembimbing, seliaan pensyarah dan kesediaan guru pelatih itu sendiri. Masalah yang dihadapi ini seterusnya telah memberikan kesan yang negatif terhadap 
Jurnal Pendidikan Awal Kanak-Kanak Kebangsaan 2017 Special Issue (16-30)

(ISSN 2289-3032 / eISSN 2550-178X)

https://ejournal.upsi.edu.my/journal/JPAK

pengalaman praktikum guru pelatih tersebut.

Persediaan guru pelatih ketika sesi praktikum dijalankan sememangnya berkait rapat dengan peranan guru pembimbing. Cunningham (2014) mengatakan guru pembimbing memainkan peranan yang besar untuk membentuk sikap, nilai dan kemahiran pengajaran guru pelatih ketika menjani latihan praktikum. Fry, Ketteridge dan Marshall (2014) mengatakan kejayaan guru pelatih dipengaruhi guru pembimbing kerana mereka berinteraksi lebih lama dengan guru pelatih berbanding pensyarah.

\section{Objektif Kajian}

Objektif kajian adalah:

1) Mengenal pasti persepsi guru pelatih terhadap seliaan guru pembimbing semasa latihan praktikum dijalankan.

2) Mengenal pasti persepsi guru pelatih terhadap seliaan pensyarah penyelia semasa menjalani praktikum.

\section{Kaedah Kajian}

Kajian yang dijalankan adalah berbentuk deskriptif. Manakala jenis penyelidikan yang dijalankan pula adalah jenis kajian tinjauan. Sampel kajian yang dikaji terdiri daripada 87 orang guru pelatih kursus Diploma Pendidikan Awal Kanak-kanak (BE102), Kolej Poly-Tech MARA di 26 buah TADIKA swasta berdaftar terpilih meliputi enam buah daerah di negeri Kelantan.

\section{Analisis Data}

Sebanyak 99 borang soal selidik telah diedarkan kepada guru pelatih apabila mereka tamat menjalani sesi latihan praktikum selama 16 minggu tetapi borang soal selidik yang dikembalikan adalah 87 set sahaja. Hasil kajian yang diperolehi adalah daripada soal selidik yang telah diedarkan kepada pelajar 
praktikum Diploma Pendidikan Awal Kanak-kanak. Data-data kajian yang diperolehi telah dianalisis menggunakan perisian Statistical Packages for Social Sciences for Windows (SPSS) versi 21.0. Pentaksiran untuk kekerapan (f), peratus (\%) dan min untuk setiap item persepsi guru pembimbing telah dilakukan.

Jadual 1: Analisis Deskriptif Persepsi Guru Pelatih Terhadap Seliaan Guru Pembimbing

\begin{tabular}{|c|c|c|c|c|c|c|}
\hline \multicolumn{7}{|c|}{$n=87$} \\
\hline Perkara & $\begin{array}{c}1 \\
f(\%)\end{array}$ & $\begin{array}{c}2 \\
f(\%)\end{array}$ & $\begin{array}{c}3 \\
f(\%)\end{array}$ & $\begin{array}{c}4 \\
f(\%)\end{array}$ & $\begin{array}{c}5 \\
f(\%)\end{array}$ & $\begin{array}{c}\text { Mi } \\
\mathbf{n}\end{array}$ \\
\hline $\begin{array}{l}\text { GP saya adalah seorang yang } \\
\text { mesra dan peramah }\end{array}$ & $\begin{array}{c}2 \\
(2.3)\end{array}$ & $\begin{array}{c}3 \\
(3.4)\end{array}$ & $\begin{array}{c}10 \\
(11.5)\end{array}$ & $\begin{array}{c}26 \\
(29.9)\end{array}$ & $\begin{array}{c}46 \\
(52.9)\end{array}$ & 4.28 \\
\hline $\begin{array}{l}\text { GP memberikan tunjuk ajar } \\
\text { yang jelas dalam aspek } \\
\text { pengurusan kelas }\end{array}$ & $\begin{array}{c}4 \\
(4.6)\end{array}$ & $\begin{array}{c}12 \\
(13.8)\end{array}$ & $\begin{array}{c}7 \\
(8.0)\end{array}$ & $\begin{array}{c}34 \\
(39.1)\end{array}$ & $\begin{array}{c}30 \\
(34.5)\end{array}$ & 3.85 \\
\hline $\begin{array}{l}\text { GP membantu membentuk } \\
\text { silaturrahim yang baik di } \\
\text { antara saya dan warga } \\
\text { TADIKA. }\end{array}$ & $\begin{array}{c}3 \\
(3.4)\end{array}$ & $\begin{array}{c}5 \\
(5.7)\end{array}$ & $\begin{array}{c}15 \\
(17.2)\end{array}$ & $\begin{array}{c}29 \\
(33.3)\end{array}$ & $\begin{array}{c}35 \\
(40.2)\end{array}$ & 4.01 \\
\hline $\begin{array}{l}\text { GP adalah seorang yang } \\
\text { berpengetahuan dan } \\
\text { berpengalaman dalam } \\
\text { pendidikan awal kanak-kanak }\end{array}$ & $\begin{array}{c}5 \\
(5.7)\end{array}$ & $\begin{array}{c}9 \\
(10.3)\end{array}$ & $\begin{array}{c}16 \\
(18.4)\end{array}$ & $\begin{array}{c}27 \\
(31.0)\end{array}$ & $\begin{array}{c}30 \\
(34.5)\end{array}$ & 3.78 \\
\hline $\begin{array}{l}\text { GP membantu saya membuat } \\
\text { perancangan pengajaran }\end{array}$ & $\begin{array}{c}11 \\
(12.6 \\
) \\
\end{array}$ & $\begin{array}{c}10 \\
(11.5)\end{array}$ & $\begin{array}{c}20 \\
(23.0)\end{array}$ & $\begin{array}{c}23 \\
(26.4)\end{array}$ & $\begin{array}{c}23 \\
(26.4)\end{array}$ & 3.43 \\
\hline $\begin{array}{l}\text { GP memberikan maklumbalas } \\
\text { yang berkesan dalam } \\
\text { meningkatkan kualiti }\end{array}$ & $\begin{array}{c}7 \\
(8.0)\end{array}$ & $\begin{array}{c}9 \\
(10.3)\end{array}$ & $\begin{array}{c}15 \\
(17.2)\end{array}$ & $\begin{array}{c}33 \\
(37.9)\end{array}$ & $\begin{array}{c}23 \\
(26.4)\end{array}$ & 3.64 \\
\hline
\end{tabular}


Jurnal Pendidikan Awal Kanak-Kanak Kebangsaan 2017 Special Issue (16-30)

(ISSN 2289-3032 / eISSN 2550-178X)

https://ejournal.upsi.edu.my/journal/JPAK

pengajaran saya di TADIKA.

\begin{tabular}{|c|c|c|c|c|c|c|}
\hline $\begin{array}{l}\text { GP melibatkan saya dalam } \\
\text { perbincangan untuk } \\
\text { menentukan aktiviti P \& P }\end{array}$ & $\begin{array}{c}5 \\
(5.7)\end{array}$ & $\begin{array}{c}12 \\
(13.8)\end{array}$ & $\begin{array}{c}18 \\
(20.7)\end{array}$ & $\begin{array}{c}34 \\
(39.1)\end{array}$ & $\begin{array}{c}18 \\
(20.7)\end{array}$ & 3.55 \\
\hline $\begin{array}{l}\text { GP berkomunikasi dan } \\
\text { melayan saya dengan } \\
\text { professional. }\end{array}$ & $\begin{array}{c}3 \\
(3.4)\end{array}$ & $\begin{array}{c}9 \\
(10.3)\end{array}$ & $\begin{array}{c}10 \\
(11.5)\end{array}$ & $\begin{array}{c}31 \\
(35.6)\end{array}$ & $\begin{array}{c}34 \\
(39.1)\end{array}$ & 3.97 \\
\hline $\begin{array}{l}\text { GP memastikan tugasan dan } \\
\text { tanggungjawab saya adalah } \\
\text { bersesuaiaan sebagai guru } \\
\text { pelatih. }\end{array}$ & $\begin{array}{c}8 \\
(9.2)\end{array}$ & $\begin{array}{c}6 \\
(6.9)\end{array}$ & $\begin{array}{c}10 \\
(11.5)\end{array}$ & $\begin{array}{c}33 \\
(37.9)\end{array}$ & $\begin{array}{c}30 \\
(34.5)\end{array}$ & 3.82 \\
\hline $\begin{array}{l}\text { GP mempunyai hubungan } \\
\text { yang baik dengan semua guru } \\
\text { dan kanak-kanak di TADIKA. }\end{array}$ & $\begin{array}{c}4 \\
(4.6)\end{array}$ & $\begin{array}{c}6 \\
(6.9)\end{array}$ & $\begin{array}{c}14 \\
(16.1)\end{array}$ & $\begin{array}{c}24 \\
(27.6)\end{array}$ & $\begin{array}{c}39 \\
(44.8)\end{array}$ & 4.01 \\
\hline
\end{tabular}

Nota:

\begin{tabular}{|l|l|}
\hline Item & Perkara \\
\hline$n$ & Jumlah Sampel Kajian \\
\hline$f$ & Kekerapan \\
\hline GP & Guru Pembimbing \\
\hline 1 & Sangat Tidak Setuju (STS) \\
\hline 2 & Tidak Setuju (TS) \\
\hline 3 & Tidak Pasti (TP) \\
\hline 4 & Setuju (S) \\
\hline 5 & Sangat Setuju (SS) \\
\hline
\end{tabular}

Berdasarkan kepada Jadual 1 di atas menunjukkan analisa dapatan kajian yang telah dibuat daripada Bahagian E soal selidik iaitu 'Kerjasama dan Maklumbalas Guru Pembimbing (GP)'. Sebanyak 10 soalan telah dianalisis 
untuk menjawab persoalan pertama kajian. Dapatan kajian menunjukkan terdapat dua persepsi yang telah diberikan oleh guru pelatih terhadap guru pembimbing iaitu persepsi yang tinggi dan sederhana. Bagi persepsi berjulat min tinggi adalah dengan data min kajian antara 3.68 - 5.0. Manakala bagi persepsi yang berjulat min sederhana pula adalah data min kajian antara 2.34 - 3.67. Pemarkatan skor min boleh dilihat pada Jadual 2 di bawah.

Jadual 2: Pemarkatan Skor Bagi Persepsi Guru Pelatih

\begin{tabular}{ll}
\hline Nilai & Tahap Persepsi \\
\hline $3.68-5.0$ & Tinggi \\
\hline $2.34-3.67$ & Sederhana \\
\hline $1.0-2.33$ & Rendah \\
\hline
\end{tabular}

(Sumber: Siti Aisyah Ramli et al. (2013). The Quality of Life of the Bahau Riverside Community: The case of the Rural Community Living along Muar and Serting Rivers)

Secara keseluruhannya, purata min bagi persoalan pertama ini adalah 3.8333. Purata dapatan tersebut menunjukkan persepsi guru pelatih terhadap guru pembimbing adalah tinggi iaitu dengan berada pada nilai antara 3.68 5.0. Guru pelatih mempunyai persepsi yang tinggi terhadap guru pembimbing.

Jadual 3: Analisis Deskriptif Persepsi Guru Pelatih Terhadap Seliaan Pensyarah Penyelia

\begin{tabular}{lcccccc}
\multicolumn{1}{c}{$n=87$} & & & & \\
\hline Perkara & $\mathbf{1}$ & $\mathbf{2}$ & $\mathbf{3}$ & $\mathbf{4}$ & $\mathbf{5}$ & Min \\
& $\boldsymbol{f ( \boldsymbol { \% } )}$ & $\boldsymbol{f ( \boldsymbol { \% } )}$ & $\boldsymbol{f ( \boldsymbol { \% } )}$ & $\boldsymbol{f ( \boldsymbol { \% } )}$ & $\boldsymbol{f ( \boldsymbol { \% } )}$ & \\
\hline Pensyarah memberi maklumat yang & 0 & 3 & 9 & 42 & 33 & 4.21 \\
jelas tentang apa yang sepatutnya & $(0.0)$ & $(3.4)$ & $(10.3)$ & $(48.3)$ & $(37.9)$ & \\
\hline
\end{tabular}


Jurnal Pendidikan Awal Kanak-Kanak Kebangsaan 2017 Special Issue (16-30)

(ISSN 2289-3032 / eISSN 2550-178X)

https://ejournal.upsi.edu.my/journal/JPAK

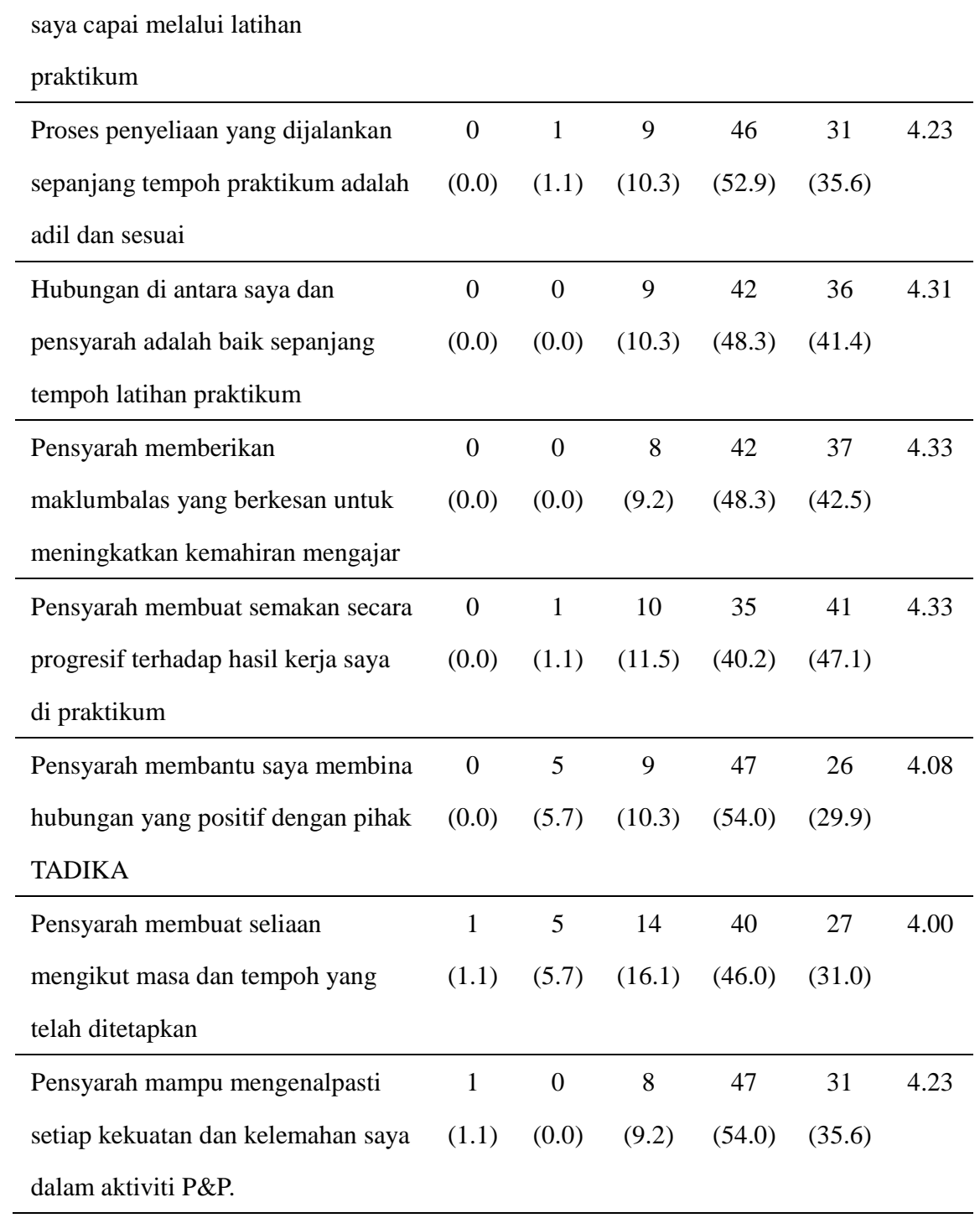

Secara keseluruhannya min purata bagi persepsi guru pelatih terhadap pensyarah penyelia semasa menjalani praktikum adalah tinggi iaitu 4.2155 dengan julat min 3.68 - 5.0. Keputusan kajian ini menunjukkan pensyarah telah menjalankan seliaan dengan baik terhadap guru pelatih ketika menjalani sesi praktikum melalui respon positif yang telah diberikan oleh guru pelatih terhadap pensyarah. Hal ini dibuktikan dengan dapatan kajian menunjukkan min tertinggi item soalan bahagian ini adalah 'Pensyarah membuat semakan 
secara progresif terhadap hasil kerja saya di praktikum'. Ketelitian pensyarah dalam menjalankan seliaan membolehkan setiap kelebihan dan kekurangan guru pelatih dikenal pasti. Guru pelatih juga boleh melakukan penambahbaikan dan baik pulih terhadap hasil kerja yang telah dipersembahkan. Peranan pensyarah penyelia turut menyumbang dalam kesediaan guru pelatih dalam memantapkan diri mereka terhadap pengajaran dan pembelajaran yang dilakukan di dalam kelas.

Secara keseluruhannya kesemua item soal selidik bahagian ini mendapat persepsi yang tinggi daripada guru pelatih iaitu meliputi persepsi julat min tertinggi antara 3.68 - 5.0. Item yang mempunyai persepsi tertinggi adalah item soalan bernombor 1 iaitu 'Praktikum mengembangkan kemahiran pengajaran melalui interaksi dan komunikasi yang positif dengan pelajar'. Min bagi soalan ini adalah 4.53, manakala kekerapan bagi item soalan pula adalah sangat setuju (SS) 48 (55.2\%), setuju (S) 37 (42.5\%), tidak pasti (TP) $2(2.3 \%)$, tidak setuju (TS) $0(0.0 \%)$ dan sangat tidak setuju (STS) $0(0.0 \%)$.

Jadual 4: Purata Min bagi Guru Pembimbing dan Pensyarah Penyelia

\begin{tabular}{lcc}
\multicolumn{1}{c}{$n=87$} & Min \\
\hline \multicolumn{1}{c}{ Perkara } & Sisihan Piawai \\
\hline $\begin{array}{l}\text { Persepsi guru pelatih terhadap guru } \\
\text { pembimbing }\end{array}$ & 3.8333 & 1.00818 \\
\hline $\begin{array}{l}\text { Persepsi guru pelatih terhadap } \\
\text { pensyarah penyelia }\end{array}$ & 4.2155 & 0.53296 \\
\hline
\end{tabular}

Jadual 4 menunjukkan purata min bagi ketiga-tiga item persoalan kajian yang telah dinilai. Dapatan kajian mendapati purata min tertinggi adalah 4.3678 bagi soalan kajian ketiga iaitu persepsi mengenai guru pelatih terhadap kesan latihan praktikum yang telah dijalankan. Diikuti dengan penilaian persepsi 
Jurnal Pendidikan Awal Kanak-Kanak Kebangsaan 2017 Special Issue (16-30)

(ISSN 2289-3032 / eISSN 2550-178X)

https://ejournal.upsi.edu.my/journal/JPAK

guru pelatih terhadap pensyarah penyelia dengan min purata pemarkatan adalah 4.2155. Manakala purata min terakhir adalah merujuk kepada persoalan pertama iaitu persepsi guru pelatih terhadap guru pembimbing. Pemarkatan purata min yang diperolehi bagi persoalan ini adalah 3.8333 .

\section{Perbincangan}

Kajian ini dijalankan bagi mengenal pasti persepsi guru pelatih terhadap guru pembimbing semasa menjalani sesi praktikum. Kajian ini turut dijalankan bagi mengenal pasti persepsi guru pelatih terhadap pensyarah penyelia. Persepsi-persepsi ini dinilai bagi mengetahui tahap seliaan praktikum yang dijalankan oleh guru pembimbing dan pensyarah penyelia terhadap guru pelatih Diploma Pendidikan Awal Kanak-kanak.

Pencapaian Objektif Pertama: Mengenal pasti persepsi guru pelatih terhadap seliaan guru pembimbing semasa latihan praktikum dijalankan.

Bagi objektif pertama, dapatan kajian menunjukkan min tertinggi kajian adalah 4.28 iaitu bagi item soal selidik 'GP saya adalah seorang yang mesra dan peramah'. Hasil kajian mendapati 72 daripada 87 orang responden bersetuju bahawa mereka mempunyai interaksi yang baik dengan guru pembimbing. Keputusan ini menunjukkan majoriti guru pembimbing praktikum merupakan seorang yang peramah. Meyers-Wagner (2015) menyatakan sesi praktikum akan membolehkan interaksi dan komunikasi antara guru pelatih dan guru pembimbing terus bertambah baik. Sikap peramah dan mudah disenangi membolehkan interaksi yang baik wujud dalam kalangan guru pelatih dan guru pembimbing. Interaksi yang baik membolehkan mereka mudah berurusan antara satu sama lain. Tanpa interaksi yang baik akan menyebabkan salah faham akan berlaku mengenai peranan guru pembimbing terhadap guru pelatih, Young dan MacPhail (2015). 
Manakala min terendah bagi pencapaian objektif ini pula adalah merujuk kepada item soalan nombor 7 'GP melibatkan saya dalam perbincangan untuk menentukan aktiviti P \& P'. Keputusan min yang dicatatkan adalah 3.55 iaitu persepsi ini berada di tahap yang sederhana. Hasil kajian menunjukkan $5.7 \%$ responden menyatakan guru pembimbing langsung tidak terlibat dalam penentuan aktiviti pengajaran dan pembelajaran guru pelatih. Ward (2015) menyatakan terdapat kelemahan dalam program penyediaan guru dilaporkan termasuklah penentuan terhadap aktiviti pengajaran dan pembelajaran di dalam kelas. Hal ini berlaku ekoran daripada guru pembimbing yang kurang memainkan peranan mereka dan hanya membiarkan guru pelatih melakukannya secara sendirian bagi proses penyediaan aktiviti pengajaran dan pembelajaran, Kagoda dan Sentongo (2015).

Pencapaian Objektif Kedua: Mengenal pasti persepsi guru pelatih terhadap seliaan pensyarah penyelia semasa menjalani praktikum.

Secara keseluruhannya, min tertinggi bagi pencapaian objektif kedua adalah merujuk kepada item soalan bernombor 5 iaitu 'Pensyarah membuat semakan secara progresif terhadap hasil kerja saya di praktikum' dengan min soalan adalah 4.33. Hasil kajian menunjukkan pensyarah menjalankan seliaan dengan baik dan progresif terhadap guru pelatih. Zbacnik (2015) mengatakan bahawa sokongan bahagian pentadbiran termasuklah pensyarah adalah penting bagi proses pengajaran guru pelatih.

Dapatan kajian juga mendapati pensyarah penyelia telah memberikan maklum balas yang berkesan untuk meningkatkan kemahiran mengajar guru pelatih di dalam kelas. Penambahbaikan dan respon positif yang telah diberikan oleh pensyarah penyelia telah membantu guru pelatih untuk merangka sesi pengajaran dan pembelajaran yang berkesan di dalam kelas. Kagoda dan Sentongo (2015) mengatakan pensyarah perlu membimbing guru 
pelatih untuk melaksanakan sesi pengajaran dan pembelajaran yang berkesan di dalam kelas. Pensyarah penyelia juga dikatakan perlu menjalinkan hubungan yang baik dengan guru pembimbing bagi melahirkan bakal pendidik yang berkaliber. Hal ini kerana sesi praktikum merupakan tempat untuk menyediakan rangka kerja bagi menjalankan program penyediaan guru yang berkualiti, Ward (2015).

\section{Kesimpulan}

Dapatan kajian mendapati guru pelatih mempunyai persepsi yang tinggi terhadap kesan latihan praktikum yang telah diikuti. Disamping itu terdapat juga persespi lain yang dinilai iaitu persepsi terhadap guru pembimbing dan persepsi terhadap pensyarah penyelia. Jones dan O'Brien (2016) menyatakan pandangan mengenai latihan praktikum yang telah dijalankan oleh guru pelatih perlu dinilai bagi memastikan program pembangunan guru mengikut dilaksanakan secara berkesan terhadap guru pelatih. Kelebihan dan kekurangan program akan dinilai.

\section{Rujukan}

Aleng, P. (2014). Transformasi pendidikan pembangunan modal insan. Selangor: PTS Akademia.

Al-Momani, F. (2016). Challenges of practicum at college of education: supervisors \& students' teachers' perspective. International Journal of Novel Research in Humanity and Social Sciences, 3(3), 45 - 52.

Allen, K. E. \& Cowdery, G. E. (2015). The exceptional child: inclusion in early childhood education, eighth edition. USA: Cengage Learning.

Altan, M. Z. \& Saglamel, H. (2015). Student teaching from the perspectives of cooperating teachers and pupils. Teacher Education \& Development Research Article, 2(1), 1 - 16.

Busher, H. et al. (2015). Student teachers' views of practicums (teacher training placements) in Turkish and english contexts: A comparative study. Compare: A 
Journal of Comparative and International Education, 45(3), 445 - 466.

Couse, L. J. \& Recchia, S. L. (2015). Handbook of early childhood teacher education. New York: Routledge Taylor \& Francis Group.

Cunningham, B. (2014). Mentoring teachers in post-compulsory education: A guide to effective practice. New York: Routledge Taylor \& Francis Group.

Fry, H., Ketteridge, S., \& Marshall, S. (2014). A handbook for teaching and learning in higher education: Enhancing academic practice $\left(4^{\text {th }}\right)$. New York: Routledge Taylor \& Francis Group.

Ihmeideh, F. \& Coughlin, C. (2015). The influence of student teachers on the perspectives of early childhood cooperating teachers regarding early reading instruction. Asia-Pacific Journal of Teacher Education, 43(3), 243 - 261.

Jones, K. \& O'Brien, J. (2016). European perspectives on professional development in teacher education. New York: Routledge Taylor \& Francis Group.

Kagoda, A. M. \& Sentongo, J. (2015). Practicing teachers' perceptions of teacher trainees: implications for teacher education. Universal Journal of Educational Research, 3(2), 148 - 153.

Khairul Anwar \& Abu Bakar. (2014). Tahap kesediaan guru pelatih Institut Pendidikan Guru dalam latihan mengajar. Skudai: Universiti Tun Hussein Onn Malaysia.

Meyers-Wagner, K. (2015). Transforming teacher preparation: A collective case study of cooperating teachers and teacher candidates in the co-teaching model of student teaching. Fullerton: California State University.

Miles, R., et al. (2016). The recursive practice of research and teaching: reframing teacher education. Asia-Pacific Journal of Teacher Education, 1 - 14.

Morrison, G. S. (2014). Early childhood education today, global edition. United Kingdom: Pearson Education, Limited.

Normah Yusof, et al. (2016). Student teachers perception towards teaching practicum programme. International Journal for Innovation Education and Research, 2(10).

Siti Aisyah Ramli et al. (2013). The quality of life of the Bahau riverside community: the case of the rural community living along Muar and Serting rivers. International Business Management, 7(2), 114 - 120. 
Jurnal Pendidikan Awal Kanak-Kanak Kebangsaan 2017 Special Issue (16-30)

(ISSN 2289-3032 / eISSN 2550-178X)

https://ejournal.upsi.edu.my/journal/JPAK

Ward, V. J. (2015). A study of the perceptions of first-year teachers as prepared classroom teachers. (Doctoral dissertation, Lindenwood University).

Young, A. M. \& MacPhail, A. (2015). 'Standing on the periphery': cooperating teachers', perceptions and responses to the role of supervision. European Physical Education Review, 21, 222-237.

Zbacnik, A. J. (2015). Co-teaching in higher education: effects on pre-service educators' academic growth and attitudes towards inclusion in special education. United States: Saint Mary's University of Minnesota. 